\title{
FORMAÇÃO DE OZÔNIO TROPOSFÉRICO: UMA REVISÃO DA LITERATURA
}

\author{
Fabiola Dayane Netto ${ }^{1}$; Luiz Carlos Daemme ${ }^{1}$; Renato Penteado ${ }^{1}$; Sérgio Machado Corrêa ${ }^{2}$; \\ Victor de Cerjat Beltrão ${ }^{1}$ e Vinícius Corcini Batista da Silva ${ }^{1}$ \\ ${ }^{1}$ Instituto de Tecnologia para o Desenvolvimento - LACTEC \\ Universidade do Estado do Rio de janeiro - UERJ
}

E-mails: fabiola.netto@lactec.org.br, luiz.carlos@lactec.org.br, renato@lactec.org.br, sergiomc@uerj.br, victor.beltrao@lactec.org.br, vinicius.silva@lactec.org.br

\begin{abstract}
A crescente preocupação em relação às emissões antropogênicas e seu impacto na qualidade do ar trouxe uma discussão mais aprofundada sobre os poluentes de formação secundária, principalmente o ozônio troposférico. Esta molécula se origina de reações fotoquímicas com radiação ultravioleta e os produtos da queima de combustíveis fósseis, como os óxidos de nitrogênio $\left(\mathrm{NO}_{\mathrm{x}}\right)$ e os compostos orgânicos voláteis $(\mathrm{COV})$. Assim como o dióxido de carbono $\left(\mathrm{CO}_{2}\right)$ levanta discussões há décadas a respeito do aumento do efeito estufa, o ozônio $\left(\mathrm{O}_{3}\right)$ também demanda atenção, principalmente quanto ao meio ambiente e patologias humanas. Estudos anteriores já mostraram forte correlação entre a concentração de ozônio em grandes centros urbanos e a incidência de complicações cardiorrespiratórias e neurológicas. $\mathrm{O}$ presente artigo traça um panorama da atual situação dos estudos relacionados à formação do ozônio troposférico como poluente secundário proveniente das emissões veiculares. Apresenta-se uma revisão da literatura dos principais artigos que tratam do assunto no âmbito nacional e internacional, apresentando ao leitor os fundamentos do estado da arte sobre o assunto.
\end{abstract}

\begin{abstract}
The increasing concern about anthropogenic emission and its impact on air quality brings a deep discussion about secondary pollutants formation, mainly related to tropospheric ozone. The origin of this molecule is the photochemical reactions between products of burning fossil fuel, such as nitrogen oxides $\left(\mathrm{NO}_{\mathrm{x}}\right)$ and volatile organic compounds (VOC), in the presence of ultraviolet radiation. Like carbon dioxide $\left(\mathrm{CO}_{2}\right)$ raises discussions for decades about the growing greenhouse effect, ozone also requires attention, mainly related to the environment and human pathologies. Previous studies have already shown strong correlations between ozone concentration in large urban centers and the incidence of cardiorespiratory and neurological complications. The present paper develops an overall picture of the current studies' situation associated to tropospheric ozone formation as a secondary pollutant produced from vehicular emissions. A literature review is presented, regarding the main articles related to the subject in both national and international scenario, presenting to the reader the state of the art fundamentals.
\end{abstract}




\section{INTRODUÇÃO}

A preocupação com a poluição gerada pelo ozônio $\left(\mathrm{O}_{3}\right)$ troposférico não é recente e a sua influência na saúde humana e na qualidade do ar atmosférico vem sendo investigada profundamente. As primeiras preocupações advindas das reações entre poluentes primários ocorreram principalmente em meados da década de 50, quando apareceram névoas de gases densos em metrópoles, que não se dissipavam e causavam forte irritação nos olhos e tosses secas. $\mathrm{O}$ fenômeno conhecido como smog fotoquímico era consequência da forte presença de gases poluentes no ar, como $\mathrm{NO}_{\mathrm{x}}, \mathrm{SO}_{2}$ e $\mathrm{COV}$, que reagiam entre si na presença de luz, formando $\mathrm{o}_{3}$. Esse efeito foi estudado especialmente em Los Angeles, local onde as condições de ventos fracos, cadeias montanhosas no entorno e alta radiação solar incidente causavam aumento de ocorrência deste fenômeno [1]. A base para a modelagem das reações químicas envolvidas no processo do smog fotoquímico foi desenvolvida na época $[2,3]$. Os resultados obtidos dos estudos foram importantes pontos de partida para a criação de órgãos legisladores de normas ambientais, como a California Air Resources Board (CARB), uma das mais restritivas agências reguladoras de emissões antropogênicas.

Atualmente é de conhecimento geral os efeitos danosos do $\mathrm{O}_{3}$ e muito se faz pelas autoridades ambientais para mitigá-los. A Organização Mundial da Saúde (OMS) publicou linhas diretivas em 2005, para aplicação global, com intuito específico de limitar a concentração máxima de $\mathrm{O}_{3}$ presente no ar. A meta para máxima concentração média em oito horas diárias de exposição a esta molécula não deve ultrapassar $100 \mu \mathrm{g} \mathrm{m}^{-3}$ para garantir uma proteção razoável à saúde humana [4]. No Brasil, cabe ao Conselho Nacional do Meio Ambiente (CONAMA) ditar as normas dos padrões de qualidade do ar. Para o CONAMA, o $\mathrm{O}_{3}$ é considerado um poluente do tipo primário, ou seja, se sua concentração limite for ultrapassada, pode afetar a saúde da população em geral. Na legislação atual, datada do ano de 1990, o valor máximo de concentração de $\mathrm{O}_{3}$ é de $160 \mu \mathrm{g} \mathrm{m}^{-3}$, em amostragem de 1 hora [5]. Pode-se notar uma clara discrepância entre as diretivas da OMS e do CONAMA, não só em relação ao $\mathrm{O}_{3}$ como de outras moléculas, o que evidencia a necessidade de reavaliação das políticas nacionais de padrões de qualidade do ar.

\section{INFORMAÇÕES GERAIS}

\subsection{Mecanismos de formação de ozônio}

A atmosfera terrestre é composta por uma mistura de gases. Dentre os átomos presentes, ressalta-se o carbono e o nitrogênio, que são átomos essenciais para a formação de compostos formadores de $\mathrm{O}_{3}$. O nitrogênio na atmosfera combina-se com o oxigênio para formar as moléculas de óxidos de nitrogênio $\left(\mathrm{NO}_{\mathrm{x}}=\mathrm{NO}+\mathrm{NO}_{2}\right)$, enquanto o carbono se junta ao oxigênio para formar os compostos orgânicos voláteis (COVs). Entende-se por compostos orgânicos voláteis qualquer composto de carbono, excluindo monóxido de carbono, dióxido de carbono, ácido carbônico, carbetos metálicos ou carbonatos e carbonato de amônio. Outra classificação refere-se a compostos de carbono gasosos, alifáticos e aromáticos, com pressão de vapor maior que $0,14 \mathrm{~mm} \mathrm{Hg}$ a $25^{\circ} \mathrm{C}$ e com carbonos na faixa de $\mathrm{C}_{2}$ a $\mathrm{C}_{12}[6,7]$.

COVs e $\mathrm{NO}_{\mathrm{x}}$ são os principais precursores de ozônio troposférico. As reações de dissociação do $\mathrm{NO}_{2}$ levam, em conjunto com a radiação solar, ao surgimento de $\mathrm{O}_{3}$. Já a degradação dos COVs leva a formação de radicais alcóxi $\left(\mathrm{RO}_{2}\right)$, hidroxila $(\mathrm{OH})$ e hidroperóxido $\left(\mathrm{HO}_{2}\right)$, que reagem com o $\mathrm{NO}$, convertendo-o em $\mathrm{NO}_{2}$. Os processos de formação de ozônio são 
complexos, porém podem ser simplificados em rotas de menor complexidade, como é apresentado a seguir [8]:

Rota 1 - Mecanismo de fotólise do $\mathrm{NO}_{2}$ :

$\mathrm{NO}_{2}+\mathrm{h} v \rightarrow \mathrm{NO}+\mathrm{O}_{(\text {atômico) }}$

$\mathrm{O}_{\text {(atômico) }}+\mathrm{O}_{2}+\mathrm{M} \rightarrow \mathrm{O}_{3}+\mathrm{M}$

$\mathrm{NO}+\mathrm{O}_{3} \rightarrow \mathrm{NO}_{2}+\mathrm{O}_{2}$

Rota 2 - Mecanismo de degradação dos COVs

$$
\begin{aligned}
& \mathrm{RH}+\mathrm{O} \rightarrow \mathrm{R}+\mathrm{H}_{2} \mathrm{O} \\
& \mathrm{R}+\mathrm{O}_{2} \rightarrow \mathrm{RO}_{2} \\
& \mathrm{HO}_{2}+\mathrm{NO} \rightarrow \mathrm{OH}+\mathrm{NO}_{2} \\
& \mathrm{RO}_{2}+\mathrm{NO} \rightarrow \mathrm{RO}+\mathrm{NO}_{2} \\
& \mathrm{RO}+\mathrm{O}_{2} \rightarrow \mathrm{R}^{\prime} \mathrm{CHO}+\mathrm{HO}_{2} \\
& \mathrm{O}_{\text {(atômico) }}+\mathrm{O}_{2}+\mathrm{M} \rightarrow \mathrm{O}_{3}+\mathrm{M}
\end{aligned}
$$

Em que hv é a radiação solar, RH são hidrocarbonetos, R'CHO são carbonilas e M são moléculas inertes, na maior parte o $\mathrm{N}_{2}$.

As diferentes velocidades de reação dos COVs presentes na atmosfera podem causar divergências significativas quanto aos seus efeitos na formação do $\mathrm{O}_{3}$ através das reações secundárias descritas. Para isso, foi criado o conceito de reatividade dos COVs para representar essas diferenças. Em adição, o cálculo de reatividade incremental foi desenvolvido para quantificar o potencial de formação de ozônio específico para cada composto. A máxima reatividade incremental (MIR) é definida como o aumento de concentração de ozônio causado pela adição de um COV a uma mistura conhecida de gases precursores de $\mathrm{O}_{3}$ [9]. O potencial de formação de $\mathrm{O}_{3}$ (OFP) é tido como a somatória de cada espécie presente no ar multiplicada pelo seu MIR, calculada através da Equação 1.

$$
\mathrm{OFP}=\Sigma \mathrm{MIRi}[\mathrm{COV}]
$$

\subsection{Influência de fatores externos na formação do ozônio}

A formação de $\mathrm{O}_{3}$ é também fortemente influenciada por condições meteorológicas e topográficas. Muitos estudos já foram feitos onde foram analisados casos específicos de grandes regiões urbanas pelo mundo.

Na cidade do Rio de Janeiro, um estudo completo de poluentes atmosféricos foi feito monitorando também fatores meteorológicos como umidade, temperatura e radiação solar. A cidade foi selecionada por ser uma das que mais ultrapassou os limites brasileiros da qualidade do ar, especificamente a região de Bangu. A Figura 1 mostra que há, conforme esperado, forte correlação entre a radiação solar e a concentração de $\mathrm{O}_{3}$ [10], resultado que corrobora com estudos prévios [11], [12]. 


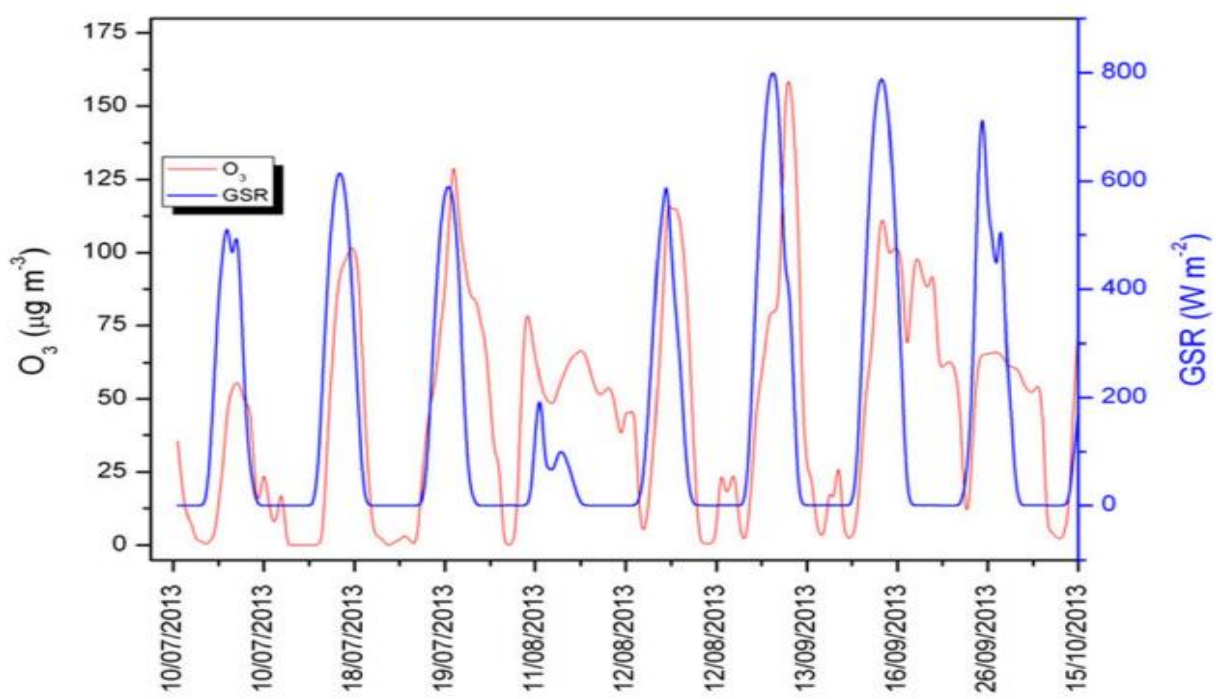

Figura 1 - Concentração de $\mathrm{O}_{3}$ e GSR (Global Solar Radiation) durante os dias de estudo [10].

Para um entendimento completo das correlações, foi desenvolvida uma análise de clusters e então demonstrada através de um dendograma pelo método de Ward. Análise de clusters pelo método de Ward é uma análise de dados onde fatores são agrupados, de forma que haja maior semelhança estatística entre eles. No diagrama, linhas próximas representam forte similaridade e, de forma análoga, linhas distantes não apresentam similaridade estatística. $\mathrm{Na}$ Figura 2 é possível observar que existem três principais grupos de similaridade. Um deles é formado pela radiação solar, temperatura, $\mathrm{PM}_{10}$, e $\mathrm{O}_{3}$, o segundo é formado pelo grupo BTEX (Benzeno, Tolueno, Etilbenzeno e Xileno) e umidade relativa, e o terceiro é composto por $\mathrm{SO}_{2}, \mathrm{NO}_{2}, \mathrm{CO}, \mathrm{NMHC}$ e $\mathrm{NO}$.

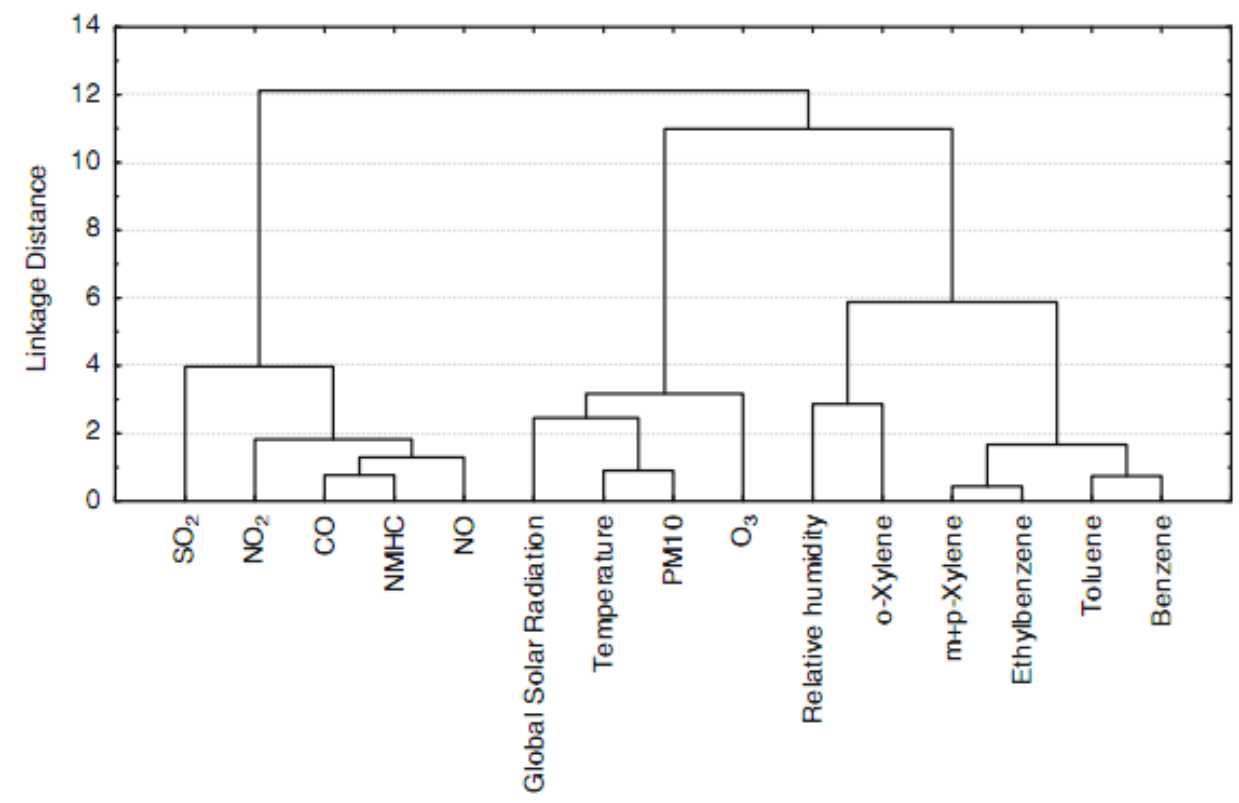

Figura 2 - Dendograma com as distâncias euclidianas pelo método de Ward entre poluentes e fatores meteorológicos [10]. 
A Tabela 1 apresenta que acetaldeído e formaldeído, juntos, correspondem a, aproximadamente, $86 \%$ da contribuição para formação de $\mathrm{O}_{3}$ baseado na escala MIR. O uso de etanol hidratado e anidro na gasolina brasileira contribuiu de modo significativo nas características da atmosfera, levando a um elevado nível atmosférico de compostos aldeídos [13].

\begin{tabular}{ccc}
\hline Componente & Contribuição MIR (\%) & MIR segundo Carter [9] \\
Acetaldeído & $\mathbf{5 8 , 0 8}$ & $\mathbf{6 , 5 4}$ \\
Formaldeído & $\mathbf{2 8 , 9 1}$ & $\mathbf{9 , 4 6}$ \\
Tolueno & $\mathbf{4 , 3 5}$ & $\mathbf{4 , 0 0}$ \\
o-Xileno & $\mathbf{3 , 1 8}$ & $\mathbf{7 , 6 4}$ \\
m-Xileno & 2,77 & $\mathbf{9 , 7 5}$ \\
p-Xileno & $\mathbf{1 , 8 1}$ & $\mathbf{5 , 8 4}$ \\
Benzeno & $\mathbf{0 , 2 0}$ & $\mathbf{0 , 7 2}$ \\
\hline
\end{tabular}

Tabela 1 - Contribuição na formação de $\mathrm{O}_{3}[10]$.

Os estudos em áreas específicas também mostraram variações cíclicas diárias e sazonais nos níveis de poluentes atmosféricos. Estas variações foram detectadas em um experimento feito em São Paulo [14]. O padrão de formação de $\mathrm{O}_{3}$, por estar ligado à radiação solar, tem altos índices em meses mais quentes, especificamente no verão e primavera. Nestas estações, por existir maior exposição diária à luz solar, os níveis de $\mathrm{O}_{3}$ persistem por mais tempo.

As variações cíclicas diárias foram presentes nos perfis de concentração de $\mathrm{NO}_{2}$ e $\mathrm{NO}$. Este comportamento está ligado ao tráfego de veículos intenso nos horários de pico já que os resultados mostraram que nas quatro estações do ano houve aumento nos níveis de $\mathrm{NO}$ e $\mathrm{NO}_{2}$ nas primeiras horas da manhã. Os perfis podem ser vistos na Figura 3. Também se nota que no inverno e outono, durante a madrugada, existem picos de concentração de $\mathrm{NO}$ e $\mathrm{NO}_{2}$. Este comportamento é causado pela estabilidade atmosférica e pouco vento [14].

Meses tipicamente úmidos também influenciam na formação de ozônio. Por ter maior incidência de chuvas, consequentemente existe maior frequência de nuvens, o que diminui a radiação solar atmosférica, acarretando uma redução na formação do poluente secundário. $\mathrm{O}$ regime de chuvas também afeta a concentração de aldeídos na atmosfera. Em dias com umidade baixa, os valores de formaldeído e acetaldeído sofrem significativos aumentos, atingindo valores máximos entre 14-16 h, tipicamente os horários mais quentes, secos e com mais radiação solar do dia [14]. Nas primeiras horas da manhã, quando há incidência de radiação solar, ocorre a fotólise do $\mathrm{NO}_{2}$ formando $\mathrm{NO}$ e $\mathrm{O}_{\text {(atômico) }}$ para, posteriormente, formar o $\mathrm{O}_{3}$, conforme já observado neste trabalho. Com o aumento significativo da radiação solar, aproximando-se das $12 \mathrm{~h}$, a reação de formação de $\mathrm{O}_{3}$ é incrementada acarretando um pico significativo do poluente. Também se observa o esgotamento de $\mathrm{NO}_{\mathrm{x}}$ e $\mathrm{NO}$ neste mesmo período de altos valores de $\mathrm{O}_{3}$. Por ser uma reação catalisada, a taxa de formação de $\mathrm{O}_{3}$ é maior, a ponto de diminuir consideravelmente a presença de $\mathrm{NO}_{\mathrm{x}}$ na atmosfera. 


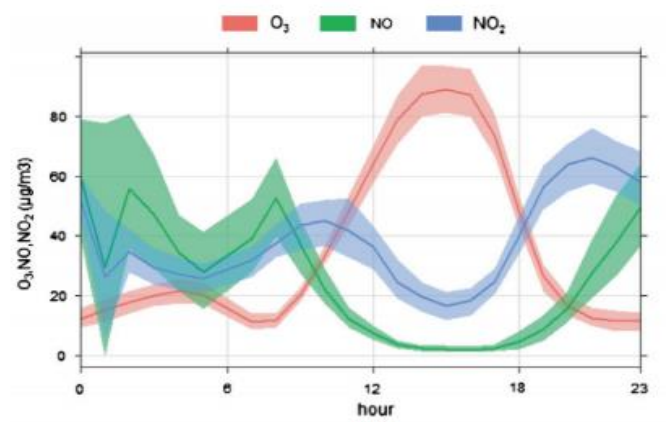

(a)

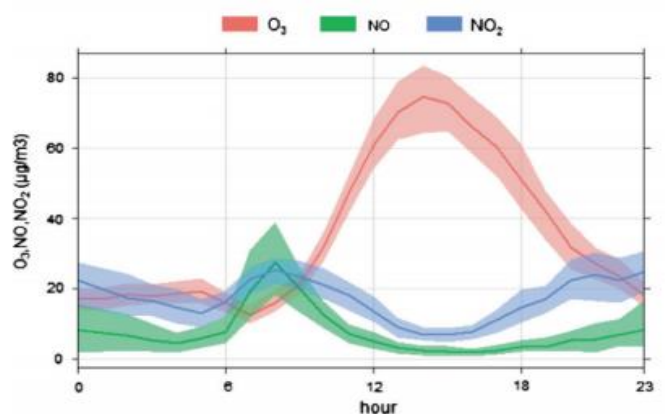

(c)

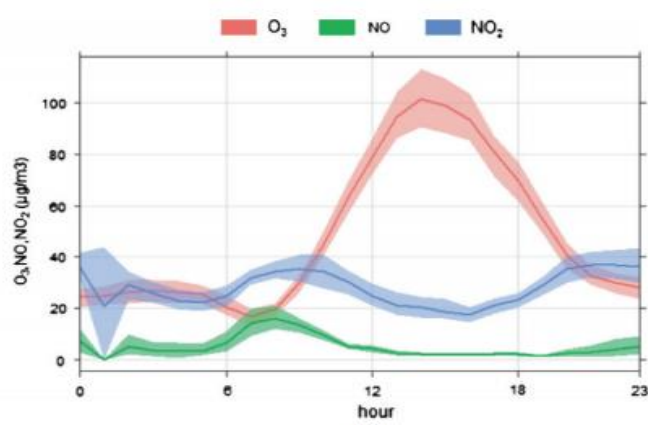

(b)

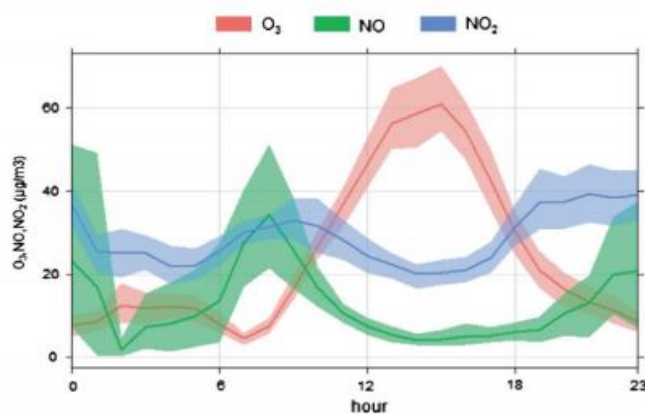

(d)

Figura 3 - Variações cíclicas diárias para $\mathrm{NO}_{2}, \mathrm{NO}$ e $\mathrm{O}_{3}$ em diferentes estações do ano: (a) inverno, (b) primavera, (c) verão e (d) outono [14].

\subsection{Ozônio relacionado aos veículos}

As emissões de poluentes provenientes da frota veicular são consideradas as mais preocupantes dentre as fontes de emissões antropogênicas. Na Europa, estima-se que as fontes veiculares representem um total de 40,5\% de emissões de $\mathrm{NO}_{\mathrm{x}}$ e $15,6 \%$ de COVs [15]. A Agência Norte Americana de Proteção Ambiental (U.S.EPA) vai mais longe, estimando um total de $61,9 \%$ de emissões $\mathrm{NO}_{\mathrm{x}}$ e $45,2 \%$ de emissões de COVs ligados a fontes veiculares nos Estados Unidos [15]. O levantamento oficial realizado para o Estado de São Paulo, por sua vez, estipula que 67,6\% das emissões de $\mathrm{NO}_{\mathrm{x}}$ são devido a fontes veiculares [16]. Os números expostos evidenciam a grande influência que os veículos possuem sobre a poluição atmosférica urbana relacionada com espécies precursoras de $\mathrm{O}_{3}$.

\subsubsection{Ozônio e emissões evaporativas}

Uma preocupação especial é considerada sobre as emissões evaporativas. Esse fenômeno é caracterizado como emissão, não atrelada ao processo de combustão, de COVs de maior volatilidade. Devido à persistentes problemas com o $\mathrm{O}_{3}$ no Brasil, o controle dessas emissões é de grande importância para impedir o aumento da presença de COVs precursores de $\mathrm{O}_{3}$ na atmosfera. São conhecidos cinco tipos de emissão evaporativa: diurna, devido ao aquecimento pela exposição do sol; a quente, durante o resfriamento do veículo; durante o abastecimento; durante o movimento do veículo; e durante o estacionamento de veículos com tanque de armazenamento confeccionados em material polimérico [17].

Uma comparação crítica das legislações atuais foi realizada em estudo recente, no qual houve análise dos limites praticados pelas agências norte americana, europeia e brasileira [18]. Em 
relação a emissão evaporativa, as informações podem ser retiradas da Tabela 2. O PROCONVE encontra-se muito defasado em comparação as outras normas. Enfatiza-se a falta de limites para as emissões de abastecimento, de movimento e de estacionamento, as quais podem aumentar substancialmente a emissão total do veículo. Além disso, os ensaios já praticados na norma atual podem não representar os valores reais de emissão pelo período de amostragem ser baixo, como no caso da emissão a quente. Tanto Estados Unidos quanto Europa exigem testes de dois ou mais dias para certificação dos veículos.

\begin{tabular}{|c|c|c|c|c|c|c|}
\hline \multirow{2}{*}{\multicolumn{2}{|c|}{ Componentes do programa }} & \multicolumn{5}{|c|}{ Valores limite } \\
\hline & & Euro 3-5 & Euro 6c & US Tier 2 & US Tier 3 & $\begin{array}{l}\text { PROCONVE } \\
\text { L6 }\end{array}$ \\
\hline \multicolumn{2}{|c|}{$\begin{array}{l}\text { NBR } 11481: 1 \mathrm{~h} \text { aquecimento do } \\
\text { tanque }+1 \mathrm{~h} \text { resfriamento a quente }\end{array}$} & & & & & $1,5 \mathrm{~g} /$ teste \\
\hline \multicolumn{2}{|c|}{$\begin{array}{c}24 \mathrm{~h} \text { diurno }+1 \mathrm{~h} \text { resfriamento a } \\
\text { quente }\end{array}$} & 2,0 g/dia & & & & \\
\hline \multicolumn{2}{|c|}{$\begin{array}{c}48 \mathrm{~h} \text { diurno }+1 \mathrm{~h} \text { resfriamento a } \\
\text { quente }\end{array}$} & & $2,0 \mathrm{~g} / \mathrm{dia}$ & $0,65 \mathrm{~g} / \mathrm{dia}$ & $0,30 \mathrm{~g} / \mathrm{dia}$ & \\
\hline \multicolumn{2}{|c|}{$\begin{array}{c}72 \mathrm{~h} \text { diurno }+1 \mathrm{~h} \text { resfriamento a } \\
\text { quente }\end{array}$} & & & $0,50 \mathrm{~g} / \mathrm{dia}$ & $0,30 \mathrm{~g} / \mathrm{dia}$ & \\
\hline \multicolumn{2}{|c|}{ Durante o movimento } & & & $0,03 \mathrm{~g} / \mathrm{km}$ & $0,03 \mathrm{~g} / \mathrm{km}$ & \\
\hline \multirow[b]{2}{*}{ Reabastecimento } & A bordo & & & $0,053 \mathrm{~g} / \mathrm{L}$ & $0,053 \mathrm{~g} / \mathrm{L}$ & \\
\hline & $\begin{array}{l}\text { Na estação de } \\
\text { abastecimento }\end{array}$ & $\begin{array}{c}90 \% \text { de } \\
\text { eficiência } \\
80-90 \% \\
\text { das } \\
\text { estações }\end{array}$ & $\begin{array}{l}90 \% \text { de } \\
\text { eficiênci } \\
\text { a } \quad 80- \\
90 \% \text { das } \\
\text { estações }\end{array}$ & $\begin{array}{c}90 \% \text { de } \\
\text { eficiência } \\
30 \% \text { das } \\
\text { estações }\end{array}$ & $\begin{array}{c}95 \% \text { de } \\
\text { eficiência } \\
\text { Califórnia } \\
\text { somente }\end{array}$ & \\
\hline
\end{tabular}

Tabela 2 - Valores limite de emissões evaporativas das legislações comparadas [18].

Um estudo realizado pela AFEEVAS analisou a possibilidade de implantação do sistema Onboard Refueling Vapor Recovery (ORVR) para diminuição de emissões no reabastecimento [17]. De acordo com os autores, para a gasolina, a emissão no reabastecimento dispensa cerca de 5,6 vezes mais hidrocarbonetos do que no escapamento do veículo. O sistema ORVR reciclaria o vapor de combustível presente no reservatório de combustível, gerando ainda benefício econômico capaz de amortizar o custo adicional do equipamento. Além deste equipamento, propôs-se a inclusão de um ciclo de testes adicional de emissões de reabastecimento para a próxima fase do PROCONVE. A emissão de COVs seria analisada em uma câmara hermética (Sealed Housing for Evaporative Determination SHED) por detectores de ionização de chama calibrados com gases padrão de referência, como já é feito atualmente para emissões de escapamento. Foi testado um veículo Ford Fusion 2.5 com o sistema ORVR embutido, encontrando-se um valor de 99,97 \% de eficiência de reabastecimento, com um total evitado de $0,107 \mathrm{~g} \mathrm{~km}^{-1}$ de poluentes emitidos. Adicionalmente, a utilização do ORVR possibilitaria evitar a necessidade de controle maior praticadas nos EUA, como medições de 24,48 e 72 horas de teste de aquecimento e resfriamento sucessivos. 


\subsubsection{Ozônio e veículos diesel}

No Brasil, na década de 70, o programa ProAlcool foi implementado visando diminuir a dependência dos países exportadores de petróleo. O programa incentivava o uso de etanol como combustível puro ou ainda em mistura com a gasolina [19]. Como consequência, o uso de Diesel em veículos leves comerciais ou de passageiros foi restringido [20]. Por conta deste panorama, empresas do setor automotivo vêm pressionando o governo brasileiro a diminuir estas restrições [21]. Embora a parcela de veículos comerciais leves a Diesel seja pequena, a sua contribuição para os valores de emissões totais da frota veicular brasileira, atualmente, é alta. Estima-se que essa representatividade é de $30 \%$ das emissões de $\mathrm{NO}_{\mathrm{x}}$, e $65 \%$ de material particulado fino [22].

As emissões de veículos leves de passageiro (LDVs) a diesel são atualmente reguladas pelo PROCONVE L6, que foi totalmente implementado em 2013. Esta norma brasileira regulatória, no que tange as emissões de $\mathrm{NO}_{\mathrm{x}}$, tem os mesmos limites usados nas normas europeias, fazendo a diferenciação entre tipos de combustíveis utilizados. Isso faz com que o carro a diesel possa emitir 33\% mais $\mathrm{NO}_{\mathrm{x}}$ que a gasolina. Já na norma norte-americana, atual Tier 2, os limites são os mesmos para qualquer tipo de combustível, diminuindo-os em $45 \%$ em relação a norma brasileira e europeia. Evidencia-se a necessidade do estudo do $\mathrm{NO}_{\mathrm{x}}$ por este ser um dos principais precursores de ozônio troposférico. Um controle contínuo das emissões de LDVs é uma estratégia importante para diminuir problemas persistentes com o $\mathrm{O}_{3}$ em grandes cidades brasileiras [23].

O estudo recente traçou um panorama das implicações que um aumento na venda de LDVs a diesel traria para a qualidade de saúde da população em geral [22]. Nesta simulação, três cenários com diferentes taxas de aumento de frota veicular a diesel foram analisados. Para o $\mathrm{NO}_{\mathrm{x}}$, os efeitos das atuais normas reguladoras de emissões veiculares refletiriam em uma redução de $30 \%$ do composto em um cenário de estabilização das vendas, mostrando os benefícios que a implementação do PROCONVE L6 trará, se mantido. A estimativa de emissões de $\mathrm{NO}_{\mathrm{x}}$ para veículos de ciclo Otto e ciclo Diesel pode ser vista na Figura 4. Em compensação, a disseminação de carros a diesel nos outros cenários traria consequências sobre a concentração de $\mathrm{NO}_{\mathrm{x}}$ na atmosfera. No cenário de dieselização rápida, com uma simulação de representação de $45 \%$ do total de vendas de LDVs pelos veículos de ciclo diesel, as emissões de $\mathrm{NO}_{\mathrm{x}}$ do diesel representariam em $84 \%$ do total de emissões deste poluente. $\mathrm{O}$ aumento exacerbado de emissões de $\mathrm{NO}_{\mathrm{x}}$ pode ser relacionado com a diferença nos fatores de emissão entre LDVs modernos a gasolina e a diesel, que chegam a ser sete vezes maiores para os veículos Euro 6 a diesel [22].

Vale ressaltar que os resultados obtidos são simulações conservadoras da realidade, devido ao fato de que há uma crescente evidência de disparidade entre medições de taxas de emissão de $\mathrm{NO}_{\mathrm{x}}$ laboratoriais e de medições de emissões em condições reais de trânsito (RDE). Estudos apresentam medições em RDE que superam substancialmente os limites estabelecidos para veículos do ciclo diesel [23] [24]. 


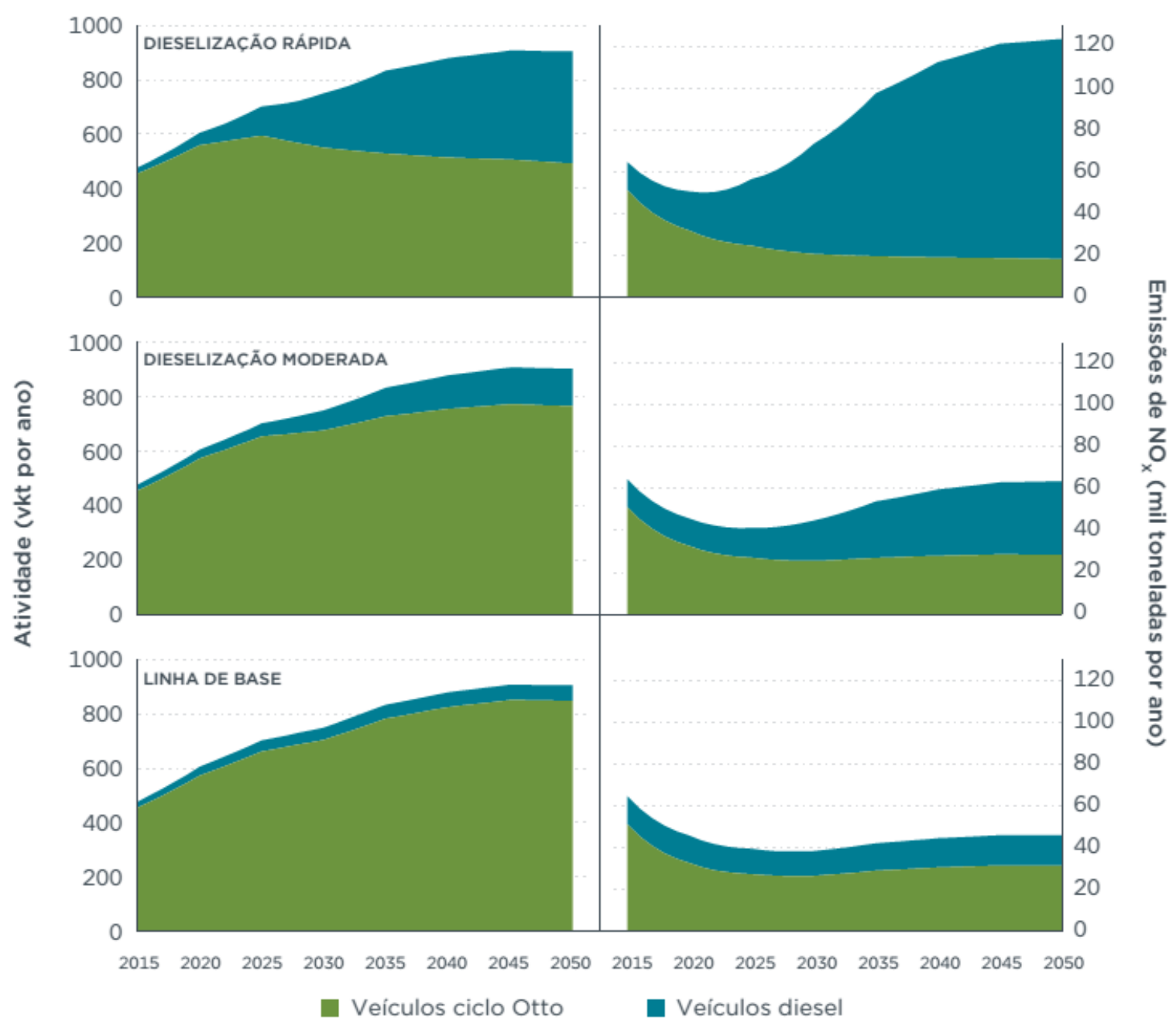

Figura 4 - Atividade projetada de LDVs (parte esquerda) e emissões de $\mathrm{NO}_{\mathrm{X}}$ (parte direita) por tipo de motor [22].

Em um estudo de emissões de COVs na China, calculou-se o OFP através de um sistema de medição de emissões portátil (PEMS) [25]. O foco do estudo foi verificar a contribuição dos COVs por quilômetro dentro de um percurso preestabelecido em veículos pesados a diesel (HDVs). Foram estudados 18 caminhões, sendo 7 de trabalho leve (LDDTS), 4 de trabalho médio (MDDTS) e 7 de trabalho pesado (HDDTS). Como esperado, as espécies dominantes pertenceram ao grupo carbonila, com números variando entre 60 a $70 \%$ do total de emissões de COVs. No cálculo dos OFP utilizando a escala MIR de Carter, os resultados indicaram um maior valor para os veículos de trabalho pesado, de 430,9 $\pm 217,7 \mathrm{mg} \mathrm{O}_{3} \mathrm{~km}^{-1}$. Os valores de OFP ultrapassaram muito os limites estipulados pela norma chinesa de $149 \mathrm{mg} \mathrm{O} \mathrm{km}^{-1}$. Ademais, a Figura 5 apresenta a comparação para os veículos ensaiados em percursos de estrada e percursos urbanos. Observou-se uma taxa de emissão de $\mathrm{O}_{3}$ menor para os veículos no trecho de estrada. Isso pode ser relacionado com a queima mais otimizada do combustível pelas maiores velocidades desenvolvidas no trecho, que reduziriam as emissões de COVs pela combustão incompleta. Pode-se considerar que os percursos urbanos contribuíram para o aumento da média de taxa de emissões total. 


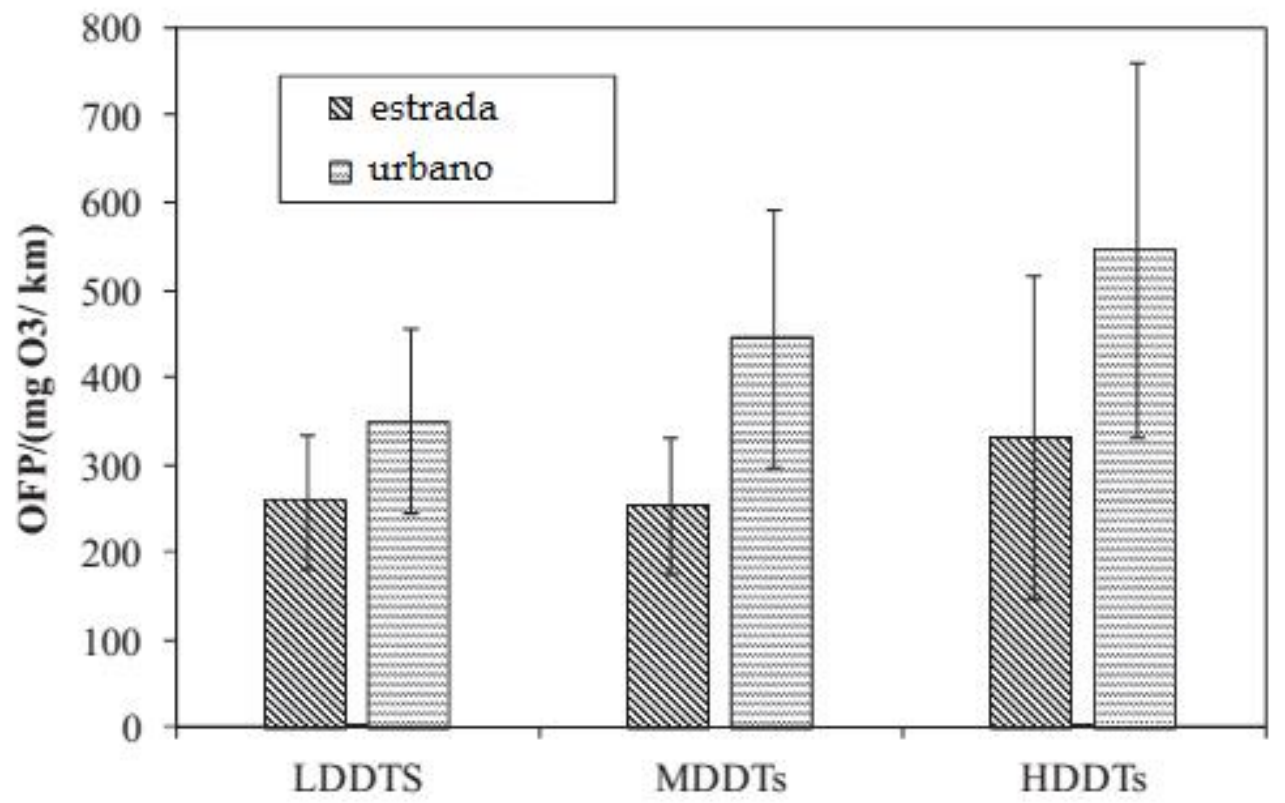

Figura 5 - Potencial de formação de ozônio para diferentes percursos [25].

Diante disso, a União Europeia introduzirá um procedimento de testes em RDE para a norma EURO 6, a ser implantado plenamente a partir de setembro de 2017. Este ciclo de testes adicional reproduzirá as condições específicas encontradas no trânsito, como mudanças de elevação e tráfego intenso, e as emissões serão analisadas através de um sistema de medição portátil (PEMS). O teste RDE usará um fator limite de não-ultrapassagem (not-to-exceed limit (NTE)) aliado aos valores já encontrados na atual norma EURO 6 para emissões durante ciclo de testes real. Esse fator levará em conta quantas vezes a emissão do veículo poderá ultrapassar o limite estipulado pela norma. Deste modo, pretende-se garantir que novos LDVs atendam aos limites sem exceder as emissões de $\mathrm{NO}_{\mathrm{x}}$ em RDE [26].

Dados de valores de emissão de $\mathrm{NO}_{\mathrm{x}}$, analisados por PEMS, de carros à diesel Euro 6, foram investigados em um estudo comparativo com um modelo de emissões computacional COPERT [27]. Foram analisados 39 LDVs em um percurso definido na Grande Área de Londres. Os veículos variaram em tamanho do motor, entre 1,4 a 3,0 litros, e em relação ao catalisador de $\mathrm{NO}_{\mathrm{x}}$ utilizado, variando entre Lean $\mathrm{NO}_{x}$ Traps (LNT), Selective Catalytic Reduction (SCR) e Exhaust Gas Recirculation (EGR). Em suma, a Figura 6 apresenta o resultado dos 39 veículos analisados. O limite estipulado pela norma Euro 6 para emissões de $\mathrm{NO}_{\mathrm{x}}$ foi ultrapassado por 22 veículos, com média de $0,17 \pm 0,19 \mathrm{~g} \mathrm{NO}_{2} \mathrm{~km}^{-1}$. Onze veículos atenderam ao NTE de 2,1 estipulado pela norma, e somente 2 ficaram abaixo do limite da Euro 6, sendo um com LNT e outro com SCR, e os dois combinados com EGR. O uso do catalisador pode chegar a atender a norma, mas muitos LDVs ainda precisam melhorar seus valores de emissões de $\mathrm{NO}_{\mathrm{x}}$ durante o ciclo real de direção. Valores de emissões reais foram majoritariamente maiores que os estimados pelo COPERT, com valor médio de $14 \%$ a mais. Essa variação, segundo os autores, poderia levar a um aumento de $8,44 \mu \mathrm{g} \mathrm{m}^{-3}$ em concentrações anuais de $\mathrm{NO}_{\mathrm{x}}$ em grandes vias com tráfego intenso. 


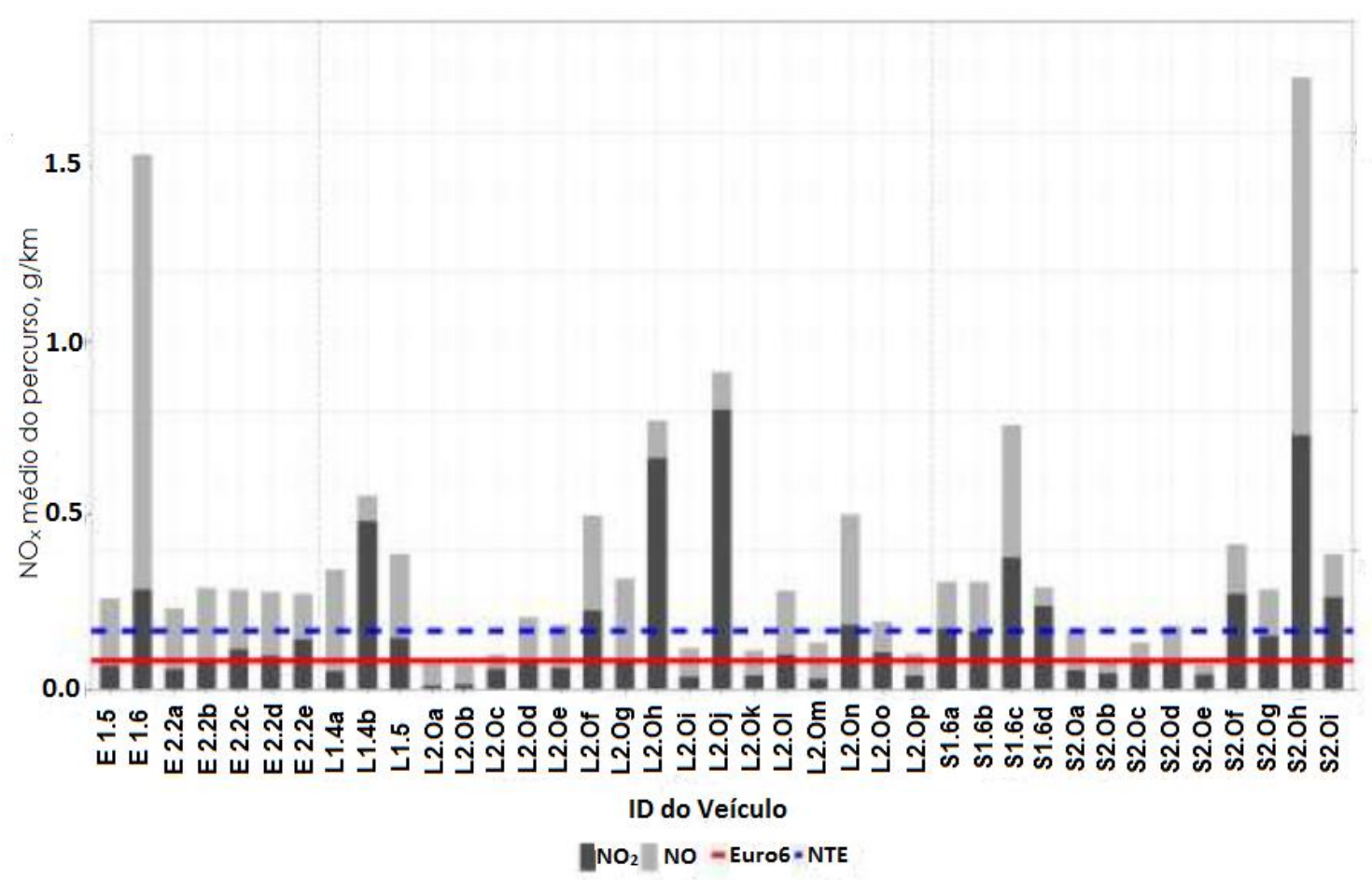

Figura 6 - Medições com PEMS mostrando valores médios de emissões de $\mathrm{NO}$ e $\mathrm{NO}_{2}$ para os 39 veículos analisados [27].

\subsubsection{Ozônio e veículos flex}

Veículos Flex foram disseminados no mercado brasileiro a partir de 2003, com apoio do governo, devido ao fato que esses veículos aumentavam o uso do etanol, que é um combustível renovável e produzido em grande quantidade no Brasil [11]. Entretanto, segundo estudo realizado, as emissões de aldeídos e álcool não queimado (ANQ) aumentam substancialmente para veículos Flex conforme se acresce a porcentagem de etanol do combustível [28]. Estudou-se também a consequência do aumento de porcentagem do etanol no combustível com o OFP em um veículo Flex [29]. Foram analisados três tipos de combustíveis nos dois estudos, sendo eles um etanol de referência EHR, uma gasolina A31 e uma gasolina A85. Os gases de escapamento foram expostos ao sol em um bag no período de 09:00 até 18:00 h de um dia para ocorrer reações de formação de $\mathrm{O}_{3}$ e consequente medição do mesmo. Como visto na Figura 7, o OFP seguiu a mesma tendência do ANQ, com variação diária de acordo com a incidência de radiação, assim como explicado na seção 1.2. Pode-se atrelar este resultado a relativamente alta reatividade do etanol e sua maior emissão de COVs.

Nesta perspectiva, muitos veículos Flex não eram capazes de atender as normas do PROCONVE para NMHC. O CONAMA então autorizou em sua Instrução Normativa $n^{\circ}$ 54/2004 o desconto da parcela de etanol não queimado das emissões de poluentes, facilitando a conformidade de novos veículos Flex a legislação. No entanto, esta prática levou a resultados incrivelmente baixos de NMHC. Apesar de o etanol não ser altamente reativo, sua 
presença em maior quantidade no ar decorrente desse desconto pode agravar a presença de $\mathrm{O}_{3}$ na atmosfera [8].

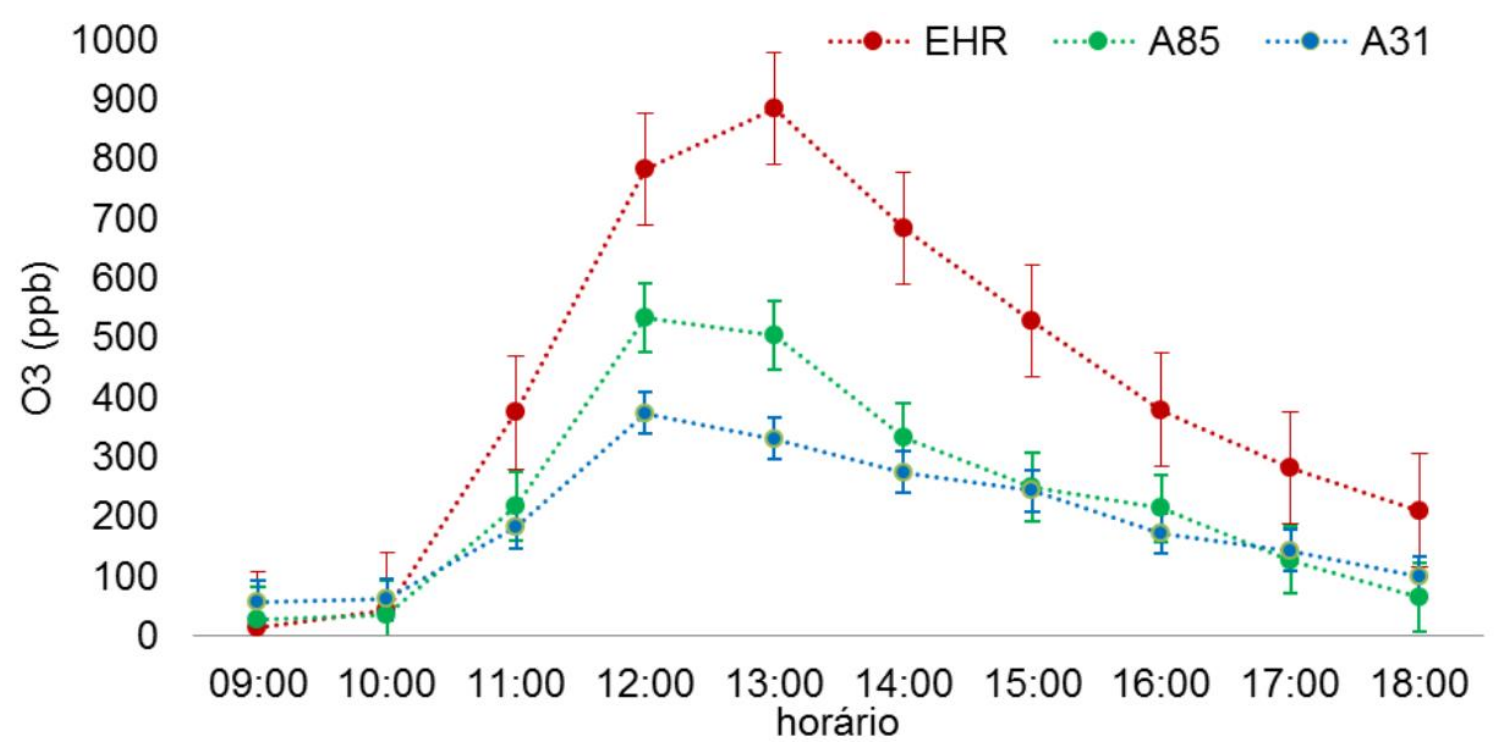

Figura 7. Médias de formação de $\mathrm{O}_{3}$ por combustível [29]

Devido a esses fatos, criou-se o Grupo de Trabalho Especial sobre o desconto do etanol não queimado, no qual propôs-se um cálculo otimizado desta parcela com base no OFP [30]. No artigo realizado com este enfoque, os autores propuseram a criação do "hidrocarboneto equivalente em $\mathrm{O}_{3}$ ". Este conceito estimaria o impacto do OFP do combustível a ser medido em comparação com o valor teórico máximo de OFP do combustível normatizado. O cálculo seria feito a partir da Equação 2:

$$
H C_{\text {equivalente }}=\frac{\sum N M O G_{i} * M I R_{i} \text { (expresso em } \frac{g_{O_{3}}}{\mathrm{~km}} \text { ) }}{\text { MIR } \left._{\text {gasolina }} \text { (expresso em } \frac{g_{O_{3}}}{g_{H C}}\right)}
$$

Deste modo, incluir-se-á o etanol não queimado medido pelo detector de ionização de chama, que segundo o estudo apresenta uma correlação maior com a emissão real dos poluentes relacionados ao etanol do veículo Flex.

Aplicando-se este conceito em estudo com 40 veículos Flex presente no mesmo artigo, descobriu-se que $30 \%$ apresentariam não-conformidade com a norma em relação ao limite de emissões de HC, utilizando o combustível E100. Isso seria devido ao desconto exagerado de etanol não queimado.

\subsubsection{Ozônio e motociclos}

Especialmente em países emergentes, onde as metrópoles ainda não ofertam um transporte coletivo de qualidade, o número de motocicletas aumentou consideravelmente nos últimos anos. Além da maior agilidade no trânsito, esta alternativa tem uma manutenção barata, baixo consumo de combustível e, geralmente, custa 20 a $25 \%$ do valor de um carro pequeno utilitário. Como exemplo deste aumento, em 2001, havia aproximadamente 82.000 
motocicletas na cidade do Rio de Janeiro, o que representava 5\% da frota total. O número aumentou para 224.000 em 2011, atingindo $9 \%$ da frota [31]. A contribuição das motocicletas para a poluição causada pelo $\mathrm{O}_{3}$ troposférico pode ser destacada devido principalmente a seus fatores de emissão historicamente altos e sua extensa presença em vias de grandes centros urbanos. Estima-se que os motociclos representem $15 \%$ das emissões de COVs da região metropolitana de São Paulo, um número que tende a aumentar com o crescimento da frota deste veículo [16].

Um estudo realizado apresentou valores preocupantes de emissões de motociclos [32]. Compararam-se as emissões de ANQ, hidrocarbonetos e aldeídos entre um levantamento da CETESB para LDVs e um motociclo Flex com dois tipos de combustível, gasolina A22 e álcool hidratado com 5,5\% de água destilada. As emissões foram medidas em dois ciclos de testes, ECE R40 e WMTC, este último considerado mais rigoroso e mais representativo do uso em cotidiano. Os resultados são observados na Figura 8. Os valores de emissão de todos os compostos avaliados para o motociclo ultrapassam substancialmente os valores obtidos para o LDV, demonstrando que a regulamentação dessas emissões para estes veículos necessita ser aprofundada.

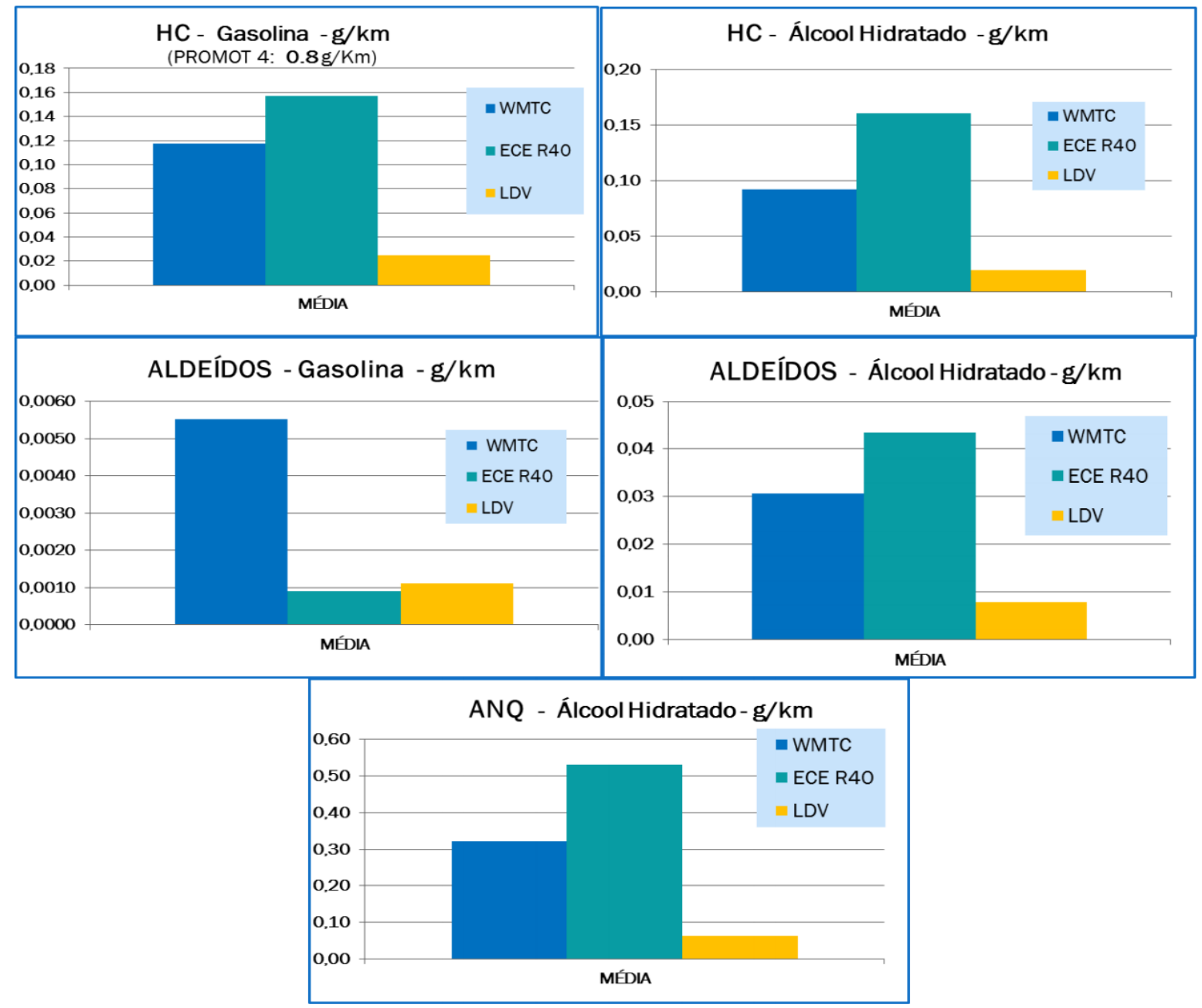

Figura 8- Comparação das emissões médias de compostos orgânicos [32]

O mesmo estudo levantou o OFP para o motociclo testado, utilizando o valor de MIR para os compostos estudados. Obteve-se um valor de OFP 30\% maior para o motociclo com etanol e 
três vezes maior que os de LDV, mostrando a necessidade de aprimoramento do motor bicombustível desse veículo. Recomendou-se que as emissões de motociclos Flex sejam estipuladas com base no OFP, assim como proposto em estudos de LDVs Flex já apresentados [30]. Isso aumentaria o rigor do controle de emissões de ANQ e aldeídos.

Levando em consideração este aumento representativo do número de motocicletas, um estudo feito em 2012 simulou um cenário para os próximos anos [31]. Para esta previsão, não foi contabilizado o aumento da frota de veículos, nem uma possível variação na composição dos combustíveis comerciais, além disso, foi desconsiderada a possibilidade da redução da emissão de poluentes por parte de motocicletas e veículos. Assim, após amostra recolhida na cidade do Rio de Janeiro foi traçado um perfil da composição atmosférica e posteriormente modelada a previsão para os próximos anos. Na Figura 9 é possível observar que em 10 anos, a partir do estudo realizado em 2012, o nível de $\mathrm{O}_{3}$ ultrapassará o nível máximo de concentração na atmosfera.

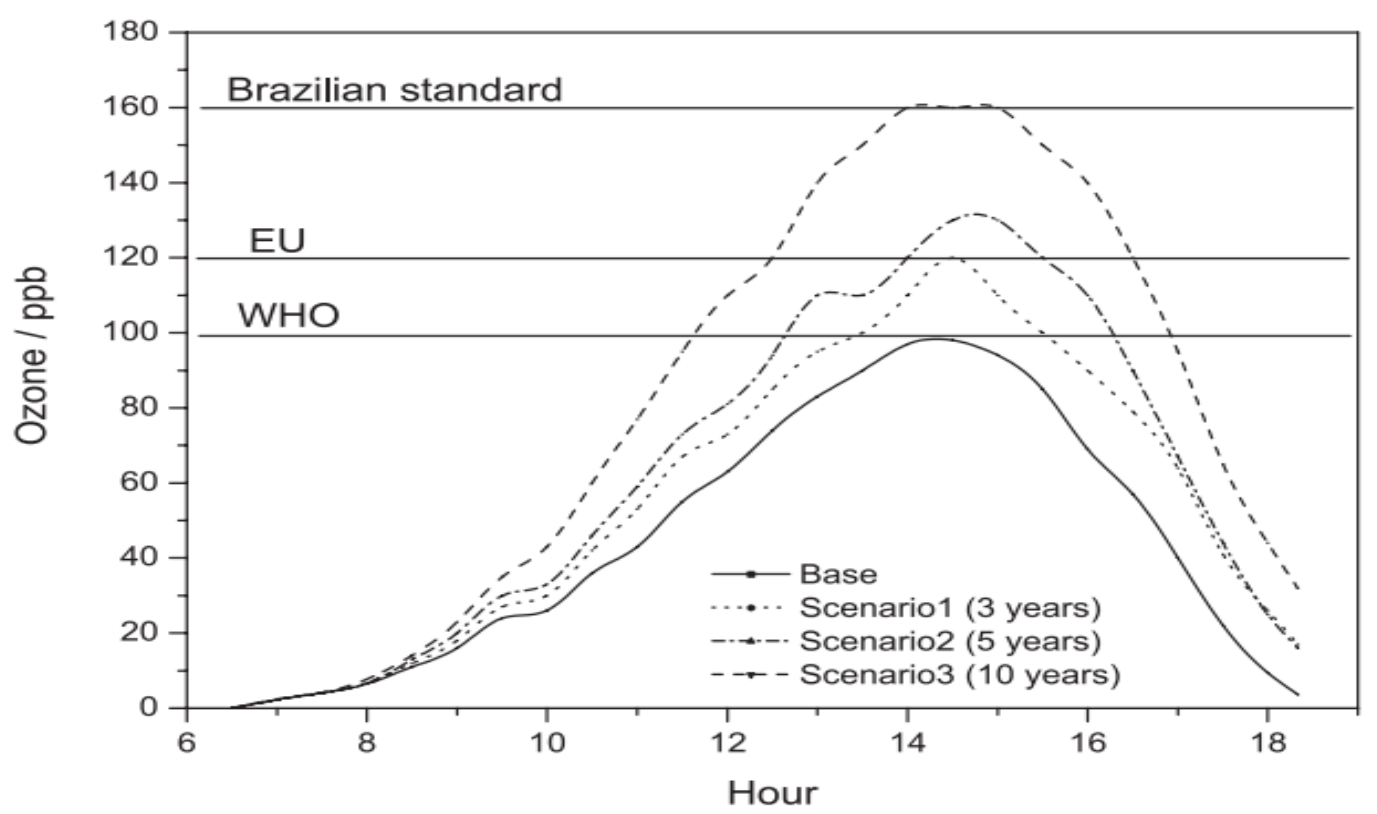

Figura 9 - Perfil de $\mathrm{O}_{3}$ modelado para os próximos anos[31].

Também é visível que o perfil de $\mathrm{O}_{3}$ corrobora com estudos anteriores mostrados neste trabalho, onde o pico de concentração ocorre no período da tarde, onde geralmente a radiação solar é também mais alta.

\subsection{Ozônio e saúde}

Pela incidência do $\mathrm{O}_{3}$ estar concentrado em centros urbanos com alta densidade demográfica, a população dessas grandes cidades é suscetível a mortes prematuras e doenças do sistema respiratório e cardiovascular.

Estima-se que no ano de 2015, somente no Brasil, ocorreram 3.109 mortes diretamente ligadas à exposição à poluição do ozônio troposférico [33]. A OMS estima que aproximadamente 21.000 mortes prematuras por ano na União Europeia (EU) estão de alguma 
forma associada com a concentração de ozônio acima de um valor de $70 \mu \mathrm{g} \mathrm{m}{ }^{-3}$, medido em média diária de 8 horas. $\mathrm{O} \mathrm{O}_{3}$ pode ser também associado a aproximadamente 14.000 admissões hospitalares por condições respiratórias na EU [34]. O Conselho Nacional de Pesquisa dos Estados Unidos recentemente publicou um estudo em que se observou, devido à grande database de estudos investigada, evidência suficiente da ligação entre mortalidade e poluição por $\mathrm{O}_{3}$ [35]. Com a clara evidência do impacto do $\mathrm{O}_{3}$ sobre a sobrevivência populacional, autores recentes buscam projetar os efeitos do $\mathrm{O}_{3}$ sobre a vida em populações futuras $[36,37]$.

As ligações entre o ozônio e problemas respiratórios vêm se tornando mais claros com a realização de experimentos de exposição controlada. Estudos conduzidos em indivíduos asmáticos foram realizados e a resposta inflamatória e funções fenotípicas no sistema imunológico foram analisadas. Os resultados mostraram que, evidentemente, a exposição ao ozônio induz a uma reação alérgica forte. Além disso, sugerem que células do sistema imunológico, como macrófagos e células dendríticas reagem de forma ineficiente a microorganismos invasores quando o indivíduo é exposto à inalação do poluente [38,39].

Alguns estudos retrospectivos recentes investigaram a relação do $\mathrm{O}_{3}$ com algumas patologias ainda não estudadas, com o objetivo de achar evidências de correlação para grandes grupos amostrais. Estudou-se a relação entre concentrações de ozônio na atmosfera e incidência de diabetes tipo 2 em mulheres afro-americanas [40]. $\mathrm{O} \mathrm{O}_{3}$ inalado muitas vezes causa estresse oxidativo nos pulmões e leva a aumento na resistência à insulina. Foram encontradas correlações positivas significantes para um nível de confiança de $95 \%$ entre exposição ao $\mathrm{O}_{3} \mathrm{e}$ incidência de diabetes, com possibilidade de afetar a saúde e qualidade de vida de mulheres. Evidenciou-se uma relação entre altas concentrações de $\mathrm{O}_{3}$ e degenerações em neurônios dopaminérgicos, o que levaria a riscos potenciais de desenvolvimento da doença de Parkinson [41]. Investigou-se a relação de aumento de exposição a longo prazo ao $\mathrm{O}_{3}$ e doença de Alzheimer em pacientes em Taiwan [42]. Um total de 95.690 indivíduos foram analisados em um estudo de coorte prospectivo. Resultados encontrados apontam que um aumento de 10.91 ppb de $\mathrm{O}_{3}$ em concentração aumentaria a chance de desenvolvimento do Alzheimer em 211\%.

\section{CONCLUSÃO}

Apesar das emissões oriundas dos veículos terem sido reduzidas substancialmente ao longo dos anos, em especial nas últimas duas décadas, com uma redução significativas das emissões primárias de monóxido de carbono, COVs e NOx, os níveis de ozônio ainda continuam elevados e com ultrapassagens rotineiras nas grandes cidades brasileiras. Isso se deve a não linearidade e complexidade apresentada pela química da atmosfera. Não é possível inferir a redução da concentração de um poluente secundário apenas pela redução de seus precursores. Mas o esforço em reduzir os precursores NOx e COVs não deve ser abandonado, pois estes também são tóxicos à saúde populacional e ao meio ambiente como um todo. Esforços concentrados devem ser direcionados à redução de espécies com maior potencial de formação de ozônio, em especial os COVs insaturados (alcenos, dienos e alcinos), aromáticos (BTEX) e oxigenados (aldeídos, cetonas e ácidos carboxílicos).

Outra linha de atuação deve ser no sinergismo entre as medidas experimentais de emissões e os estudos de modelagem, tanto a nível de combustão como de química da atmosfera, para que ferramentas como modelos de qualidade do ar possam prover a sociedade de respostas a 
eventos futuros, como a entrada de novas misturas de combustíveis fósseis e renováveis, novos catalisadores, sistemas anti-evaporação, novos controles de trânsito (como rodízios de veículos), eventos meteorológicos extremos, dentre outros fatores.

\section{REFERÊNCIAS}

[1] TIAO, G. C.; BOX, G. E. P.; HAMMING, W. J. Analysis of Los Angeles photochemical smog data: a statistical overview. Journal of the Air Pollution Control Association, v. 25, n. 3, p. 260-268, 1975.

[2] HAAGEN-SMIT, A. J.; BRADLEY, C. E.; FOX, M. M. Ozone formation in photochemical oxidation of organic substances. Industrial \& Engineering Chemistry, v. 45, n. 9, p. 2086-2089, 1953.

[3] HAAGEN-SMIT, A. J. Chemistry and physiology of Los Angeles smog. Industrial \& Engineering Chemistry, v. 44, n. 6, p. 1342-1346, 1952.

[4] WHO. WHO air quality guidelines for particulate matter, ozone, nitrogen dioxide and sulfur dioxide. Global update 2005. Genebra: WHO, 2006.

[5] IEMA. Estudo de padrões da qualidade do ar. Relatório completo disponível em http://www.energiaeambiente.org.br/wp-content/uploads/2015/09/padroes-final01.pdf. Acesso em 30 de março de 2017.

[6] EPA. Technical Overview of Volatile Organic Compounds. Disponível em https://www.epa.gov/indoor-air-quality-iaq/technical-overview-volatile-organic-compounds.

Acesso em 15 de abril de 2017.

[7] WATSON, J. G.; CHOW, J. C.; FUJITA, E. M. Review of volatile organic compound source apportionment by chemical mass balance. Atmospheric Environment, v. 35, n. 9, p. 1567-1584, 2001.

[8 DE MELO, T. C. C., LOUREIRO, L. N., VICENTINI, P. C., SANTOS, E. M., ALMEIDA, J. C. S. Fator de reatividade dos gases de escapamento para formação de ozônio-metodologia e resultados de veículos nacionais com gasolina e GNV. Blucher engineering proceedings, n. 1, 2013.

[9] CARTER, W.P. L. Development of ozone reactivity scales for volatile organic compounds. Air \& waste, v. 44, n. 7, p. 881-899, 1994.

[10] DA SILVA, D. B.N.; MARTINS, E. M.; CORRÊA, S. M. Role of carbonyls and aromatics in the formation of tropospheric ozone in Rio de Janeiro, Brazil. Environmental monitoring and assessment, v. 188, n. 5, p. 1-13, 2016.

[11] SILVA, K. C. C. Estudo de emissões legisladas, álcool não queimado e potencial de formação de ozônio de um veículo leve bicombustível. LACTEC. Curitiba, 2014. [12] ALVIM, D. S., GATTI, L. V., SANTOS, M. H. D., YAMAZAKI, A. Estudos dos compostos orgânicos voláteis precursores de ozônio na cidade de São Paulo. Eng Sanit Ambient, v. 16, n. 2, p. 189-196, 2011.

[13] DO CARMO RANGEL, M.; CARVALHO, M. F. A. Impacto dos catalisadores automotivos no controle da qualidade do ar. Química Nova, v. 26, n. 2, p. 265-277, 2003. [14] NOGUEIRA, T., DOMINUTTI, P. A., DE CARVALHO, L. R. F., FORNARO, A., DE FATIMA ANDRADE, M. Formaldehyde and acetaldehyde measurements in urban tmosphere impacted by the use of ethanol biofuel: Metropolitan Area of Sao Paulo (MASP), 20122013. Fuel, v. 134, p. 505-513, 2014.

[15] GALVÃO, E. S. Influência dos compostos orgânicos voláteis no potencial de formação do ozônio troposférico na Grande Vitória-ES. Vitória, 2014. 
[16] CETESB. Relatório de Qualidade do Ar no Estado de São Paulo-2016. Secretaria do Meio Ambiente, Série Relatórios, ISSN 0103-4103, São Paulo, 2017.

[17] SZWARC, A., FARAH, E. L., BRANCO, G. M., \& BRANCO, F. C. Redução da emissão evaporativa do veículo em movimento e no reabastecimento de combustível.

Simpósio Internacional de Engenharia Automotiva, v. 22, 2014.

[18] DALLMANN, T., FAÇANHA, C. International comparison of Brazilian regulatory standards for light-duty vehicle emissions. The International Council on Clean

Transportation, 2017.

[19] ANDRADE, E. T.; CARVALHO, S. R. G.; SOUZA, L. F. Programa do Proálcool e o etanol no Brasil. Engevista, v. 11, n. 2, 2010.

[20] DEPARTAMENTO NACIONAL DE COMBUSTÍVEIS (DNC). (1994). Portaria $\mathrm{N}^{\mathbf{o}} 23$, de 6 de Junho de 1994. Disponível em http://www.camara.gov.br/sileg/integras/409721.pdf. Acesso em 20 de abril de 2017.

[21] APROVE DIESEL. (2015). Aliança Pró-Veículos Diesel. Disponível em http://aprovediesel.com.br/site/index.html. Acesso em 15 de abril de 2017.

[22] DALLMANN, T.; FAÇANHA, C. Environmental risks of diesel passenger vehicles in Brazil. The International Council on Clean Transportation, 2016.

[23] FRANCO, V., SÁNCHEZ, F. P., GERMAN, J., MOCK, P. Real-world exhaust emissions from modern diesel cars. Communications, v. 49, n. 30, p. 847129-102, 2014.

[24] CHEN, Y.; BORKEN-KLEEFELD, J. Real-driving emissions from cars and light commercial vehicles-Results from 13 years remote sensing at Zurich/CH. Atmospheric Environment, v. 88, p. 157-164, 2014.

[25] YAO, Z., SHEN, X., YE, Y., CAO, X., JIANG, X., ZHANG, Y., HE, K. On-road emission characteristics of VOCs from diesel trucks in Beijing, China. Atmospheric Environment, v. 103, p. 87-93, 2015.

[26] International Council on Clean Transportation. A technical summary of Euro 6/VI vehicle emission standards. Disponível em www.theicct.org/briefing-technical-summaryeuro6-vi. Acesso em 11 de abril de 2017.

[27] O'DRISCOLL, R. S., APSIMON, H. M., OXLEY, T., \& MOLDEN, N. Portable Emissions Measurement System (PEMS) data for Euro 6 diesel cars and comparison with emissions modelling. Journal of Earth Sciences and Geotechnical Engineering, v. 6, n. 4, p. 15-28, 2016.

[28] SILVA, K. C., DAEMME, L. C., MACEDO, V., PENTEADO, R., CORRÊA, S. M., LACTEC, I., CONSULTORIA, P. K. Estudo das emissões de álcool não queimado e aldeídos em veículo Flex analisadas pelas técnicas de Cromatografia e FTIR. Anais do XXII Simpósio Internacional de Engenharia Automotiva-SIMEA, p. 471-480, 2014. [29] SILVA, K. C., DAEMME, L. C., MACEDO, V., PENTEADO, R., CORRÊA, S. M., LACTEC, I., CONSULTORIA, P. K. Avaliação da tendência à formação de ozônio dos gases de escapamento de um veículo abastecido com combustíveis contendo diferentes teores de etanol. Blucher Engineering Proceedings, v. 1, n. 2, p. 449-461, 2014.

[30] BRANCO, G. M., SZWARC, A., BRANCO, F. C., \& NIGRO, F. E. B. Controle de emissão de compostos orgânicos com base no potencial de formação de ozônio. Blucher Engineering Proceedings, v. 1, n. 1, p. 637-654, 2013.

[31] GARCIA, L. F., CORREAA, S. M., PENTEADO, R., DAEMME, L. C., GATTI, L. V., \& ALVIM, D. S. Measurements of emissions from motorcycles and modeling its impact on air quality. Journal of the Brazilian Chemical Society, v. 24, n. 3, p. 375-384, 2013.

[32] SZWARC, A., BRANCO, G. M., DA CRUZ, J. A., ROMIO, R., FAGGI, R., DO SUL, V. D. A. Medição da emissão de aldeídos e álcool não queimado em motocicletas operando 
nos ciclos WMTC e ECE R40. Blucher Engineering Proceedings, v. 1, n. 2, p. 224-234, 2014.

[33] INSTITUTE FOR HEALTH METRICS AND EVALUATION. (2016). Global Burden of Disease. Results by location, cause, and risk factor. Seattle, United States. Disponível em http://www. healthdata.org/gbd. Acesso em 18 de abril de 2017.

[34] AMANN, M. Health risks of ozone from long-range transboundary air pollution. WHO Regional Office Europe, 2008.

[35] NATIONAL RESEARCH COUNCIL. Estimating mortality risk reduction and economic benefits from controlling ozone air pollution. National Academies Press, 2008. [36] PHYSICK, W.; COPE, M.; LEE, S. The impact of climate change on ozone-related mortality in Sydney. International journal of environmental research and public health, v. 11, n. 1, p. 1034-1048, 2014.

[37] WILSON, A., REICH, B. J., NOLTE, C. G., SPERO, T. L., HUBBELL, B., RAPPOLD, A. G. Climate change impacts on projections of excess mortality at 2030 using spatially varying ozone-temperature risk surfaces. Journal of Exposure Science and Environmental Epidemiology, v. 27, n. 1, p. 118-124, 2017.

[38] ALEXIS, N. E., LAY, J. C., HAZUCHA, M., HARRIS, B., HERNANDEZ, M. L.,

BROMBERG, P. A., PEDEN, D. B. Low-level ozone exposure induces airways inflammation and modifies cell surface phenotypes in healthy humans. Inhalation toxicology, v. 22, n. 7, p. 593-600, 2010.

[39] LAY, J. C., ALEXIS, N. E., KLEEBERGER, S. R., ROUBEY, R. A., HARRIS, B. D., BROMBERG, P. A., PEDEN, D. B. Ozone enhances markers of innate immunity and antigen presentation on airway monocytes in healthy individuals. Journal of Allergy and Clinical Immunology, v. 120, n. 3, p. 719-722, 2007.

[40] JERRETT, M., BROOK, R., WHITE, L. F., BURNETT, R. T., YU, J., SU, J., COOGAN, P. F. Ambient ozone and incident diabetes: A prospective analysis in a large cohort of African American women. Environment International, v. 102, p. 42-47, 2017. [41] KIRRANE, E. F., BOWMAN, C., DAVIS, J. A., HOPPIN, J. A., BLAIR, A., CHEN, H., WARD, M. H. Associations of ozone and PM2.5 concentrations with Parkinson's disease among participants in the Agricultural Health Study. Journal of occupational and environmental medicine. American College of Occupational and Environmental Medicine, v. 57, n. 5, p. 509, 2015.

[42] JUNG, C.-R; LIN, Y.-T., HWANG, B.-F. Ozone, particulate matter, and newly diagnosed Alzheimer's disease: a population-based cohort study in Taiwan. Journal of Alzheimer's Disease, v. 44, n. 2, p. 573-584, 2015. 